\title{
Synthesis and characterization of bio-based benzoxazines derived from thymol
}

\author{
Yelda Ertas Dogan, ${ }^{1}$ Bekir Satilmis, ${ }^{1,2}$ Tamer Uyar $\mathbb{C}^{1}$ \\ ${ }^{1}$ Institute of Materials Science and Nanotechnology, UNAM-National Nanotechnology Research Center, Bilkent University, Ankara, \\ 06800, Turkey \\ ${ }^{2}$ Department of Chemistry, Faculty of Science and Arts, Ahi Evran University, Kirsehir, 40100, Turkey \\ Correspondence to: T. Uyar (E-mail: uyar@unam.bilkent.edu.tr)
}

ABSTRACT: In the present study, bio-based benzoxazine resins were synthesized from bio-based phenolic compound; thymol, and three different amines; ethylamine, aniline and 1,6-diaminohexane, and paraformaldehyde by solvent-free condensation reaction. The chemical structures of bio-based benzoxazines; T-ea (thymol, ethylamine), T-a (thymol, aniline), and T-dh (thymol, 1,6-diaminohexane) were characterized by proton nuclear magnetic resonance spectroscopy, Fourier transform infrared (FTIR) spectroscopy, elemental analysis, and high-resolution mass spectrometry. The curing studies of T-ea, T-a, and T-dh bio-based benzoxazines were performed by stepwise thermal treatment at $150,175,200,225$, and $250{ }^{\circ} \mathrm{C}$. The polymerization (ring-opening and crosslinking reactions) of $\mathrm{T}$-ea, $\mathrm{T}$-a, and T-dh bio-based benzoxazines was investigated by FTIR spectroscopy. Cure analysis was conducted using differential scanning calorimetry and the changes in thermal properties of the T-ea, T-a, and T-dh bio-based benzoxazine resins and their corresponding thermally crosslinked polybenzoxazines PT-ea, PT-a, and PT-dh were studied by thermogravimetric analyzer. The results indicated that all the thymol-based polybenzoxazines have shown enhanced thermal stability. @ 2018 Wiley Periodicals, Inc. J. Appl. Polym. Sci. 2019, $136,47371$.

KEYWORDS: bio-based benzoxazine; polybenzoxazines; solventless synthesis; thermal properties; thymol

Received 1 October 2018; accepted 29 October 2018

DOI: 10.1002/app.47371

\section{INTRODUCTION}

Benzoxazines have received growing attention due to their excellent processability and rich molecular design flexibility. ${ }^{1-6}$ Until recently, benzoxazine resins have been synthesized from petroleum-based phenolic derivatives, formaldehyde and primary amines either in solution or by a melt-state reaction. ${ }^{7}$ However, petroleum-based phenolics are nonrenewable resources and scarcity of these materials has heightened the need for novel benzoxazines that can be developed and commercialized to reduce the widespread dependence on fossil fuels. ${ }^{8}$ Recently, several naturally occurring phenolic compounds have been used for the synthesis of bio-benzoxazines including cardanol, ${ }^{9-21}$ guiacol, ${ }^{22-25}$ urushiol, ${ }^{26,27}$ eugenol, ${ }^{17,28-30}$ vanillin, ${ }^{31}$ cardbisphenol, ${ }^{32}$ resorcinol, ${ }^{33}$ arbutin, ${ }^{34}$ lignin, ${ }^{35}$ chavicol, ${ }^{36}$ coumarin, ${ }^{37}$ rosin, ${ }^{38}$ and chalcone. ${ }^{39}$ These types of phenolic compounds are plant-derived and widely found in variety of plants. Although several plant-derived phenolic compounds were utilized, ${ }^{40-45}$ to the best of our knowledge, thymol has not been used as a phenolic derivative for the synthesis of the benzoxazine resins. Therefore, thymol is a white crystalline compound found in thyme and other various plants was used in this study to produce bio-benzoxazine resins. ${ }^{46-49}$
Traditionally, synthesis of benzoxazine resins is achieved by heating a solution of a mixture of appropriate primary amine, phenolic derivative, and formaldehyde. ${ }^{7}$ However, in this type of synthesis method, the necessary solvent may cause extensive formation of oligomers and limited solubility which are two main shortcomings that may lead low yield and make the purification process challenging. ${ }^{50}$ Therefore, in this study, a solventless synthesis procedure was applied to prepare the bio-benzoxazine resins using thymol compound. As it is known, most of the benzoxazines are synthesized as monofunctional and difunctional molecules from monophenols or aromatic bisphenols with monoamines or diamines, and formaldehyde. As benzoxazines have molecular design flexibility, the desired characteristics of benzoxazines can be achieved with polyfunctionality and by introducing special functional groups in the benzoxazine structure. In this research, thymol-based bio-benzoxazine resins were synthesized from three different amines with different functionalities (aliphatic, aromatic, and difunctional aliphatic) to investigate the effect of functional groups on the thermal properties of the bio-benzoxazines and their polybenzoxazines. Furthermore, chemical and thermal characterizations were performed for these bio-benzoxazine resins and their crosslinked polybenzoxazine networks after curing. 


\section{EXPERIMENTAL}

\section{Materials}

Paraformaldehyde (Sigma-Aldrich, Germany, 95\%), ethylamine (Fluka, UK, 70 wt \% in water), aniline (Sigma-Aldrich, Germany, 99.5\%), 1,6-diaminohexane (Sigma-Aldrich, Germany, 98\%), thymol (Alfa Aesar, Germany, $\geq \% 98$ ), deuterated dimethyl sulfoxide [ $d_{6}$-DMSO, deuteration degree min. $99.8 \%$ for nuclear magnetic resonance (NMR) spectroscopy, Merck, Germany], and potassium bromide $[\mathrm{KBr}, 99 \%$, Fourier transform infrared (FTIR) grade, Sigma-Aldrich, Germany] were obtained from commercial suppliers and used as received.

\section{Synthesis of Thymol-Based Benzoxazine Resins}

Solventless synthesis method ${ }^{30,32}$ was employed for the preparation of bio-benzoxazines which were produced using thymol as a phenolic derivative and three types of amine with different functionalities, aniline (aromatic), ethylamine (aliphatic), and 1,6-diaminohexane (difunctional) were used as starting materials. In brief, amine (aniline and ethylamine; $40 \mathrm{mmol}$ and 1,6-diaminohexane; $20 \mathrm{mmol})$, paraformaldehyde $(80 \mathrm{mmol})$, and thymol $(40 \mathrm{mmol})$ were mixed and stirred at room temperature to obtain a homogenous solution. Then, the mixture was heated up to $110{ }^{\circ} \mathrm{C}$ and kept at this temperature for $2 \mathrm{~h}$. Afterward, it was cooled down to room temperature. The following are the observed physical properties and characterization data for particular bio-benzoxazine resins.

Thymol-Ethylamine-Based Bio-Benzoxazine Resin. Thymolethylamine (T-ea) was formed as pale orange viscous liquid with a yield of $92.5 \%$. Characterization of T-ea was summarized as follows; ${ }^{1} \mathrm{H}$ NMR ( $d_{6}$-DMSO, ppm): 6.88-6.64 (d, 2H), $4.76(\mathrm{~s}, 2 \mathrm{H})$, $3.80(\mathrm{~s}, 2 \mathrm{H}), 3.13(\mathrm{~m}, 1 \mathrm{H}), 2.67(\mathrm{t}, 3 \mathrm{H}), 2.07(\mathrm{~s}, 3 \mathrm{H})$, and $1.10(\mathrm{~m}$, 9H); FTIR $\left(\mathrm{KBr}, \mathrm{cm}^{-1}\right): 2961,2872,1609,1582,1492,1455$, $1384,1349,1253,1222,1149,1028,966,945,805,753$, and $692 \mathrm{~cm}^{-1}$. Calculated values of elemental composition of T-ea $\left(\mathrm{C}_{14} \mathrm{H}_{21} \mathrm{NO}\right)$ are \% C: 76.67, \% H: 9.64, \% N: 6.38 and observed percentages of $\mathrm{C}, \mathrm{H}$, and $\mathrm{N}$ for $\mathrm{T}$-ea were $75.29,8.82$, and 6.31 , respectively. Mass spectroscopy results are $(\mathrm{M}+\mathrm{H})^{+}$calculated: 220.1695; observed: 220.1705.

Thymol-Aniline-Based Bio-Benzoxazine Resin. Thymol-aniline (T-a) was obtained as pale orange waxy solid with a yield of $83 \%$. Characterization of T-a was summarized as follows; ${ }^{1} \mathrm{H}$ NMR $\left(d_{6^{-}}\right.$ DMSO, ppm): 7.24-7.16 (m, 5H), 6.93-6.68 (m, 2H), 5.39 (s, 2H), $4.51(\mathrm{~s}, 2 \mathrm{H}), 3.13(\mathrm{~m}, 1 \mathrm{H}), 2.17(\mathrm{~s}, 3 \mathrm{H})$, and $1.10(\mathrm{~m}, 9 \mathrm{H})$; FTIR $\left(\mathrm{KBr}, \mathrm{cm}^{-1}\right): 2960,2868,1601,1496,1455,1375,1250,1223,1168$, $1046,972,943,811,753$, and $692 \mathrm{~cm}^{-1}$. Calculated values of elemental composition of $\mathrm{T}-\mathrm{a}\left(\mathrm{C}_{18} \mathrm{H}_{21} \mathrm{NO}\right)$ are \% C: $80.86, \% \mathrm{H}: 7.91$, $\% \mathrm{~N}: 5.23$ and observed percentages of $\mathrm{C}, \mathrm{H}$, and $\mathrm{N}$ for $\mathrm{T}$-a were $80.45,7.94$, and 5.39 , respectively. Mass spectroscopy results are $(\mathrm{M}+\mathrm{H})^{+}$calculated: 268.1695; observed: 268.1700.

Thymol-Diaminohexane-Based Bio-Benzoxazine Resin. Thymol-diaminohexane (T-dh) was produced as pale yellow highly viscous liquid with a yield of $92 \%$. Characterization of T$\mathrm{dh}$ was summarized as follows; ${ }^{1} \mathrm{H}$ NMR $\left(d_{6}\right.$-DMSO, ppm): 7.06-6.76 (m, 4H), 4.89 (s, 4H), 3.81 (s, 4H), $3.13(\mathrm{~m}, 2 \mathrm{H}), 2.80$ $(\mathrm{m}, 4 \mathrm{H}), 2.20(\mathrm{~s}, 6 \mathrm{H}), 1.45(\mathrm{~m}, 8 \mathrm{H})$, and $1.10(\mathrm{~m}, 9 \mathrm{H})$; FTIR
$\left(\mathrm{KBr}, \mathrm{cm}^{-1}\right): 2953,2864,1613,1580,1490,1457,1359,1251$, $1226,1147,1112,1051,966,947,805$, and $753 \mathrm{~cm}^{-1}$. Calculated values of elemental composition of T-dh $\left(\mathrm{C}_{30} \mathrm{H}_{44} \mathrm{~N}_{2} \mathrm{O}_{2}\right)$ are \% C: 77.54, \% H: 9.54, \% N: 6.03 and observed percentages of $\mathrm{C}, \mathrm{H}$ and $\mathrm{N}$ for $\mathrm{T}$-dh were $75.87,8.76$, and 6.18 , respectively. Mass spectroscopy results are $(\mathrm{M}+\mathrm{H})^{+}$calculated: 465.3475 ; observed: 465.3479 .

\section{Curing Studies of the Bio-Based Benzoxazine Resins}

Around $1 \mathrm{~g}$ of T-ea, T-a, and T-dh was placed in a standard oven and stepwisely heated to programmed temperature of 150,175 , 200,225 , and $250{ }^{\circ} \mathrm{C}$ to provide opening and crosslinking of the oxazine ring in the structure of bio-based benzoxazine resins with thermal curing. All samples were kept for $1 \mathrm{~h}$ in each temperature step and small amount of sample was taken from each bio-based benzoxazine at $150,175,200,225$, and $250{ }^{\circ} \mathrm{C}$ separately to investigate the ring-opening and crosslinking reaction occurred at each temperature step. FTIR was used to investigate the structural changes occurring after heating at each step of thermal curing.

\section{Characterization and Measurements}

The chemical structures of the synthesized thymol-based benzoxazine resins were confirmed by using ${ }^{1} \mathrm{H}-\mathrm{NMR}$ spectrometer (DPX-400, Bruker). Samples were prepared by dissolving $\sim 20 \mathrm{mg} \mathrm{mL}{ }^{-1}$ in $d_{6}$-DMSO and the ${ }^{1} \mathrm{H}$-NMR frequency of $400 \mathrm{MHz}$. FTIR spectroscopy was used for the investigation of both structural characterization and structural changes occurring during the thermally induced ring-opening polymerization for thymol-based benzoxazine resins. FTIR spectra were taken by Bruker-VERTEX 70 spectrometer and recorded with 64 scans at a resolution of $4 \mathrm{~cm}^{-1}$ within $4000-400 \mathrm{~cm}^{-1}$ range. Samples were prepared by mixing the benzoxazine resins with $\mathrm{KBr}$ in a ratio $\sim 3: 100$ ( $3 \mathrm{mg}$ sample: $100 \mathrm{mg} \mathrm{KBr}$ ) and then compressed to form pellets. Cure analysis of the samples was performed using differential scanning calorimetry (DSC, TA Q2000, UK). The samples were first equilibrated at $25{ }^{\circ} \mathrm{C}$ then heated up to $350{ }^{\circ} \mathrm{C}$ at $20{ }^{\circ} \mathrm{C} / \mathrm{min}$ under $\mathrm{N}_{2}$ atmosphere. Thermal properties of the thymol-based benzoxazine resins before and after the curing were investigated by thermogravimetric analyzer (TGA, Q500; TA Instruments, UK). The TGAs were performed at a $20^{\circ} \mathrm{C} \mathrm{min}-1$ heating rate by starting from room temperature to $800{ }^{\circ} \mathrm{C}$ for all samples. Char yield (CY) of the samples was also calculated from TGA thermograms. Elemental analyses were carried out by using a Thermo Scientific Flash 2000 series CHNS-O analyzer. 2,5-[Bis (5-tert-butyl-2-benzoxazol-2-yl)] thiophene $\left(\mathrm{C}_{26} \mathrm{H}_{26} \mathrm{~N}_{2} \mathrm{SO}_{2}\right)$ and vanadium (V) oxide were used as a standard and a catalyst, respectively. High resolution mass spectroscopy (Agilent Technologies 6224 Time-of-flight liquid chromatography-mass spectroscopy, TOF LC/MS, UK) was used to determine the molecular weight of the benzoxazine compounds. Samples were first dissolved in chloroform and then diluted in acetonitrile for the measurement.

\section{RESULTS AND DISCUSSION}

\section{Structural Characterization of the Thymol-Based Bio- Benzoxazine Resins}

Thymol-based benzoxazine resins namely, T-ea, T-a, and T-dh were synthesized by condensation reactions of thymol, paraformaldehyde 


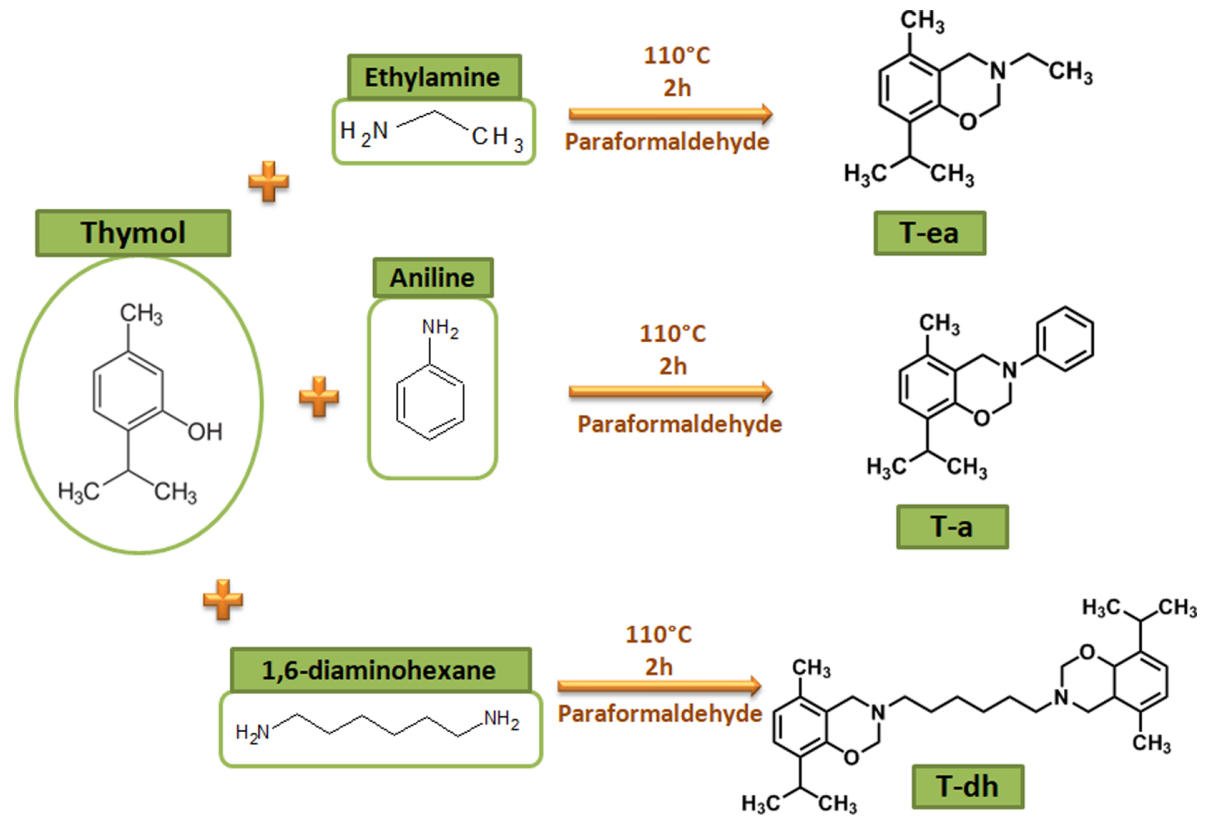

Figure 1. Synthesis of thymol-based bio-benzoxazine resins. [Color figure can be viewed at wileyonlinelibrary.com]

and with three different functional amines; ethylamine (aliphatic), aniline (aromatic), and 1,6-diaminohexane (difunctional) (Figure 1). Although all bio-benzoxazine resins were obtained as yellow liquid, T-dh was highly viscous then the others which might be possibly due to its higher molecular weight. The solubility of thymol-based benzoxazines were tested using different solvents and they were found to be soluble in acetone, chloroform, $\mathrm{N}, \mathrm{N}$-dimethylformamide, DMSO, $\mathrm{N}, \mathrm{N}$-dimethylacetamide, toluene, and tetrahydrofuran indicating that they possess good solution processability.

The chemical structures of the thymol-based bio-benzoxazine resins are confirmed by ${ }^{1} \mathrm{H}-\mathrm{NMR}$ and FTIR spectroscopy. Figure 2 represents the proposed chemical structures and ${ }^{1} \mathrm{H}$ NMR spectra of T-ea, T-a, and T-dh. As it is well-documented, the formation of the benzoxazine structure is confirmed by the appearance of two new resonance peaks of methylene protons in the oxazine ring with $1: 1$ ratio in the ${ }^{1} \mathrm{H}-\mathrm{NMR}$ spectrum. ${ }^{50}$ Accordingly, the resonance peaks attributed to the $\mathrm{Ph}-\mathrm{CH}_{2}-\mathrm{N}$ and $\mathrm{O}-\mathrm{CH}_{2}-\mathrm{N}$ methylene protons of the oxazine ring were observed at around 5.39 and $4.51 \mathrm{ppm}, 4.76$ and $3.80 \mathrm{ppm}, 4.89$ and $3.81 \mathrm{ppm}$ in the ${ }^{1} \mathrm{H}-\mathrm{NMR}$ spectra of T-ea, T-a, and T-dh, respectively. The existence of these resonance peaks with 1:1 ratio confirms the formation of the oxazine ring and that proves the synthesis of desired thymol-based benzoxazine resins. The oxazine ring resonance peaks of $\mathrm{T}$-ea and $\mathrm{T}$-dh were observed at very similar ppm values when compared to $\mathrm{T}-\mathrm{a}$, presumably the high shielding effect of the benzene ring in the structure of $\mathrm{T}-\mathrm{a}$ compared to aliphatic groups in the structure of T-ea and T-dh. The resonance peaks of all protons found in the structure of the thymol-based bio-benzoxazine resins are displayed in the ${ }^{1} \mathrm{H}$ NMR spectra of each compound verifying the synthesis of the desired thymol-based benzoxazine resins (Figure 2).

Besides ${ }^{1} \mathrm{H}-\mathrm{NMR}$, the formation of benzoxazine structure was also confirmed by FTIR spectroscopy. FTIR spectra of the T-ea, (a)

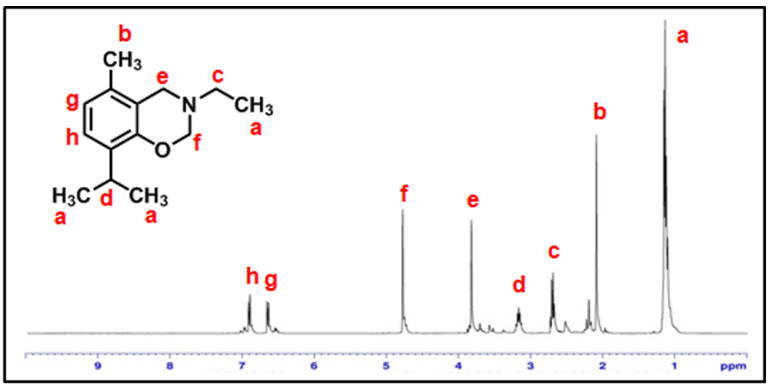

(b)

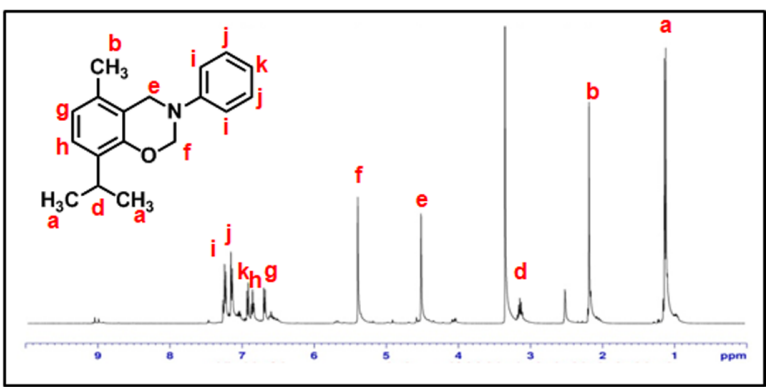

(c)

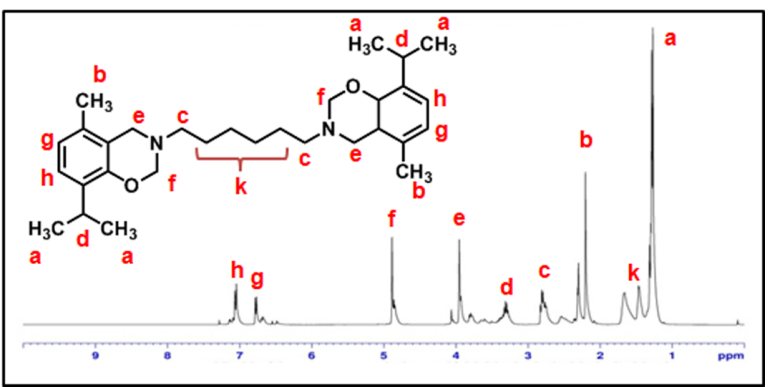

Figure 2. The proposed chemical structures and ${ }^{1} \mathrm{H}-\mathrm{NMR}$ spectra of thymol-based benzoxazines. (a) T-ea, (b) T-a, and (c) T-dh. [Color figure can be viewed at wileyonlinelibrary.com] 

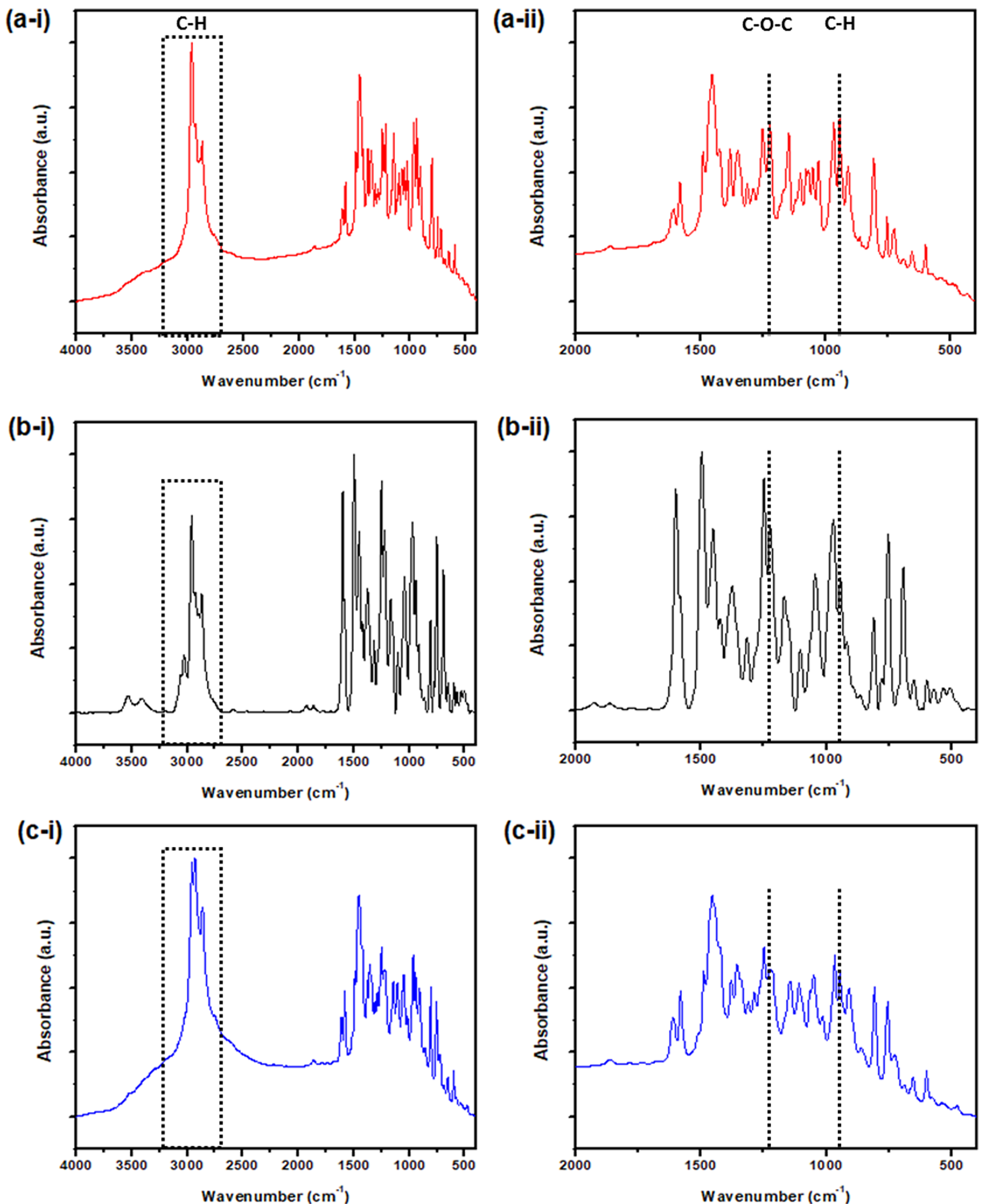

Figure 3. FTIR spectra of (a) T-ea, (b) T-a, and (c) T-dh, (i) in the range of 4000-400 $\mathrm{cm}^{-1}$ and (ii) in the range of $2000-400 \mathrm{~cm}^{-1}$. [Color figure can be viewed at wileyonlinelibrary.com] 
(a)

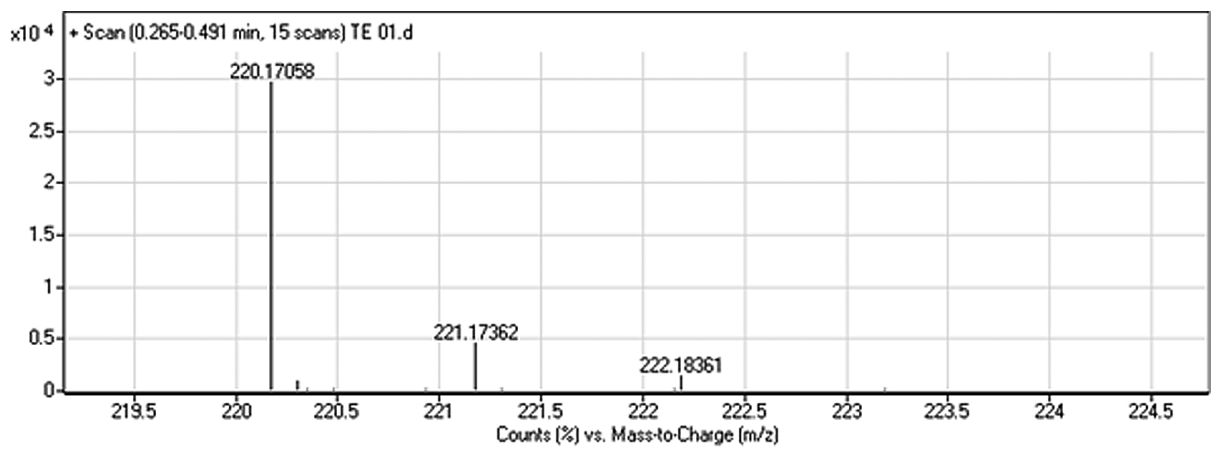

(b)

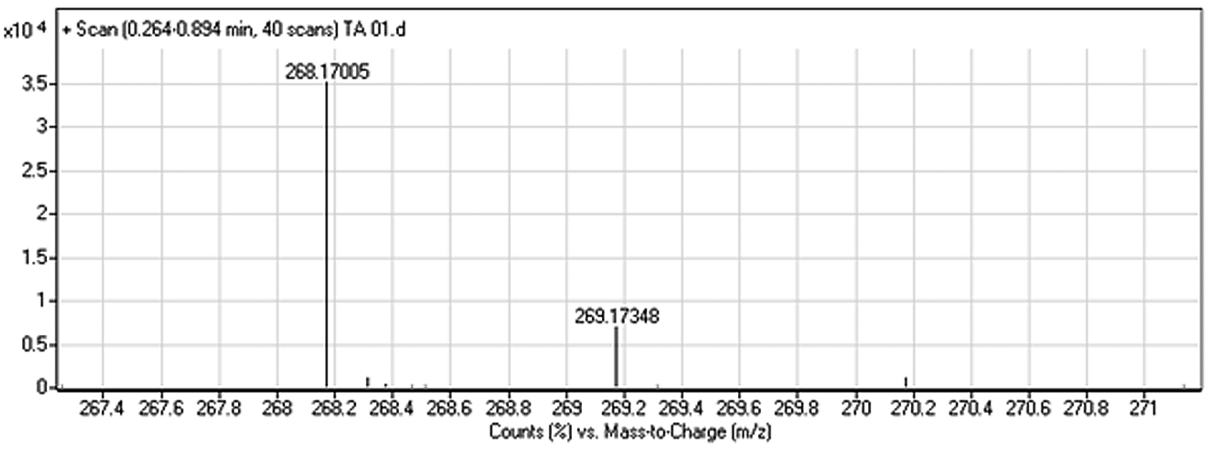

(c)

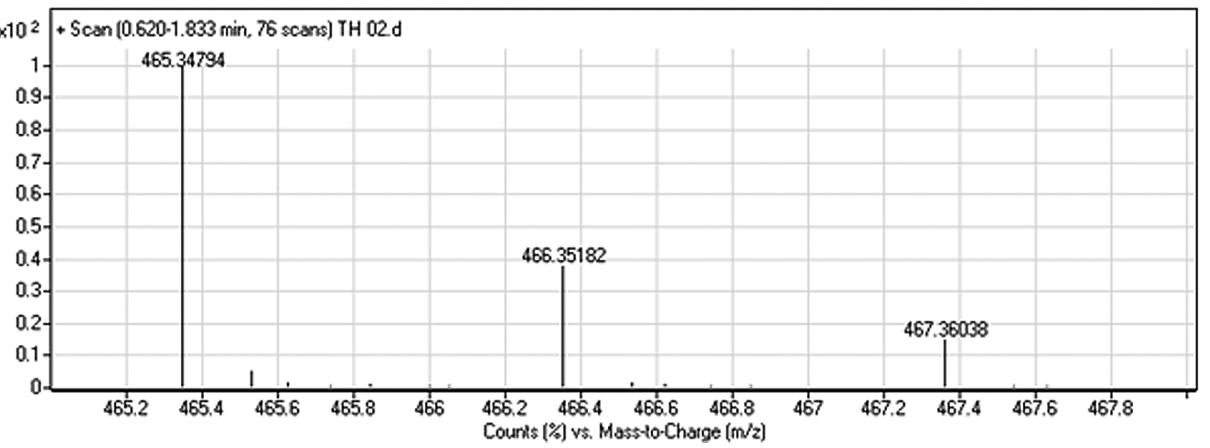

Figure 4. Mass spectra of (a) T-ea; $[\mathrm{M}+\mathrm{H}]^{+}$(calculated): 220.1695, $[\mathrm{M}+\mathrm{H}]^{+}$(observed): 220.1705, (b) $\mathrm{T}$-a; $[\mathrm{M}+\mathrm{H}]^{+}$(calculated): $268.1695,[\mathrm{M}+\mathrm{H}]^{+}$ (observed): 268.1700, and (c) T-dh; [M+ H] $]^{+}$(calculated): 465.3475, [M+ H $]^{+}$(observed): 465.3479.

T-a, and T-dh are presented in Figure 3. The FTIR spectrum of T-ea shows characteristic oxazine ring absorbance peak at $1222 \mathrm{~cm}^{-1}$ attributed to the asymmetric stretching of $\mathrm{C}-\mathrm{O}-\mathrm{C}$ [Figure 3(a)]. ${ }^{51}$ The other characteristic peak observed at $945 \mathrm{~cm}^{-1}$ is attributed to the $\mathrm{C}-\mathrm{H}$ out-of-plane deformation mode of the benzene ring attached to the oxazine ring. ${ }^{51}$ The spectrum also shows a sharp peak at $1492 \mathrm{~cm}^{-1}$ due to in-plane deformation mode of three-substituted benzene ring and peak at $1349 \mathrm{~cm}^{-1}$ due to tetrasubstituted benzene ring. The peaks between 2961 and $2872 \mathrm{~cm}^{-1}$ attributed to the asymmetric and symmetric stretching vibrations of the alkyl side chains of thymol and ethyl amine. Similarly, FTIR spectrum of T-a demonstrates characteristic oxazine ring peaks at $1223 \mathrm{~cm}^{-1}$ attributed to the asymmetric of C-O-C [Figure 3(b)]. The other characteristic peak observed at $945 \mathrm{~cm}^{-1}$ attributed to the $\mathrm{C}-\mathrm{H}$ out-of-plane deformation mode of the benzene ring attached to the oxazine ring. ${ }^{51}$ The spectrum also shows a sharp and intense peak at $1496 \mathrm{~cm}^{-1}$ due to in-plane deformation mode of three-substituted benzene ring and peak at $1375 \mathrm{~cm}^{-1}$ due to tetrasubstituted benzene ring. $\mathrm{C}-\mathrm{H}$ stretching vibration of benzene ring appears at 3060 and $3026 \mathrm{~cm}^{-1}$. Asymmetric and symmetric stretching vibrations of the methylene group of the oxazine ring and alkyl side chain of thymol are observed between 2960 and $2868 \mathrm{~cm}^{-1}$. Likewise, FTIR spectrum of T-dh shows characteristic oxazine ring absorbance peak at $1226 \mathrm{~cm}^{-1}$ attributed to the asymmetric stretching vibration of $\mathrm{C}-\mathrm{O}-\mathrm{C}$ [Figure $3(\mathrm{c})$ ]. The other characteristic peak at $947 \mathrm{~cm}^{-1}$ attributed to the $\mathrm{C}-\mathrm{H}$ out-of-plane deformation mode of the benzene ring attached to the oxazine ring. The spectrum also shows a sharp peak at $1490 \mathrm{~cm}^{-1}$ due to inplane deformation mode of three-substituted benzene ring. ${ }^{35}$ Other peaks between 2953 and $2864 \mathrm{~cm}^{-1}$ attributed to the asymmetric and symmetric stretching vibrations of the methylene group of the oxazine ring, alkyl side chain of thymol and 1,6-diaminohexane. The FTIR spectra of T-ea, T-a, and T-dh are consistent with ${ }^{1} \mathrm{H}$-NMR spectra and confirming the synthesis of the proposed thymol-based benzoxazine resins. 
Table I. Atomic Weight Percentages of Elements in Synthesized Thymol-Based Bio-Benzoxazines

\begin{tabular}{|c|c|c|c|c|c|}
\hline & Benzoxazine & N (\%) & C (\%) & $H(\%)$ & $\mathrm{O}(\%)$ \\
\hline \multirow[t]{3}{*}{ Experimental values } & T-ea & 6.31 & 75.29 & 8.83 & NA \\
\hline & $\mathrm{T}-\mathrm{a}$ & 5.40 & 80.45 & 7.94 & NA \\
\hline & T-dh & 6.18 & 75.88 & 8.76 & NA \\
\hline \multirow[t]{3}{*}{ Theoretical values } & T-ea & 6.39 & 76.67 & 9.65 & 7.29 \\
\hline & $\mathrm{T}-\mathrm{a}$ & 5.24 & 80.86 & 7.92 & 5.98 \\
\hline & T-dh & 6.03 & 77.54 & 9.54 & 6.88 \\
\hline
\end{tabular}

NA, not applicable (O \% was not measured experimentally).

Mass spectra of thymol-based benzoxazines are given in Figure 4. Calculated and observed mass values $(\mathrm{M}+\mathrm{H})^{+}$of $\mathrm{T}$-ea (calculated: 220.1695; observed: 220.1705.), T-a (calculated: 268.1695; observed: 268.1700), and T-dh (calculated: 465.3475; observed: 465.3479) are almost identical indicating the successful synthesis of the proposed bio-benzoxazine molecules. In addition to the mass spectroscopy analyses, elemental composition of thymolbased benzoxazines was also investigated. Table I summarizes the experimental and theoretical weight percentage of each element found in the structure of T-ea, T-a, and T-dh. As depicted in Table I, experimental and theoretical values are in good agreement confirming the successful synthesis of desired molecules of thymol-based benzoxazine resins. Negligible differences in the elemental compositions might be originated from the unreacted species. However, this is not a disadvantage for the benzoxazines because unreacted species especially, phenols behave as a catalyst during the thermal curing and decrease the polymerization temperature. ${ }^{7}$<smiles>CCN1COc2c(C(C)C)ccc(C)c2C1</smiles>

\section{T-ea}<smiles>Cc1ccc(C(C)C)c2c1CN(c1ccccc1)CO2</smiles>

T-a $150^{\circ} \mathrm{C}+175^{\circ} \mathrm{C}+200^{\circ} \mathrm{C}$ $+225^{\circ} \mathrm{C}+250^{\circ} \mathrm{C}$

Curing

$150^{\circ} \mathrm{C}+175^{\circ} \mathrm{C}+200^{\circ} \mathrm{C}$

$+225^{\circ} \mathrm{C}+250^{\circ} \mathrm{C}$

Curing<smiles>CCN(Cc1c(C)c(C(C)C)cc(C(C)(C)C)c1O)CC(C)(C)C</smiles>

PT-ea<smiles>Cc1c(C(F)(F)F)cc(C(C)C)c(O)c1CN(CC(C)(C)C)c1ccccc1</smiles>

PT-a

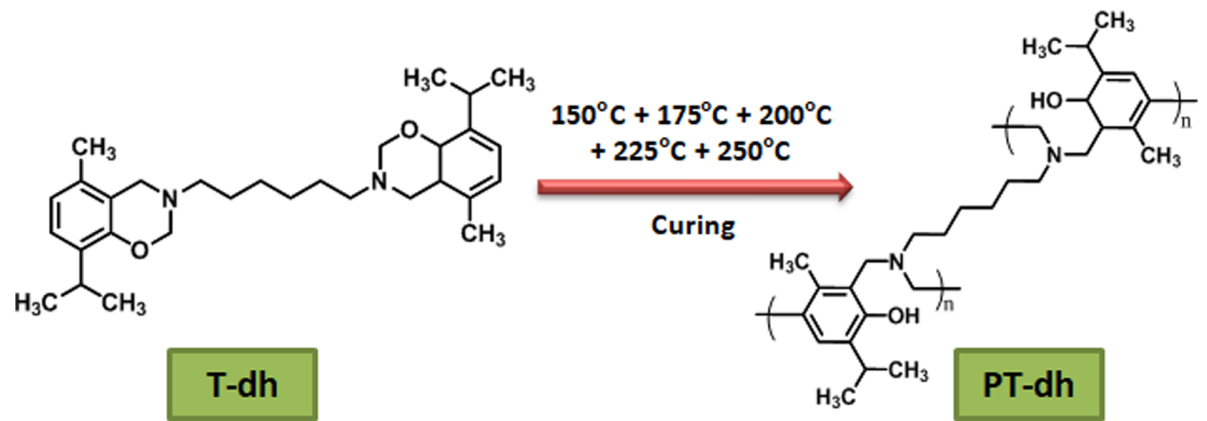

Figure 5. Polymerization of thymol-based bio-benzoxazine resins with thermally initiated ring-opening reaction. [Color figure can be viewed at wileyonlinelibrary.com] 
$\mathrm{O}-\mathrm{H}$

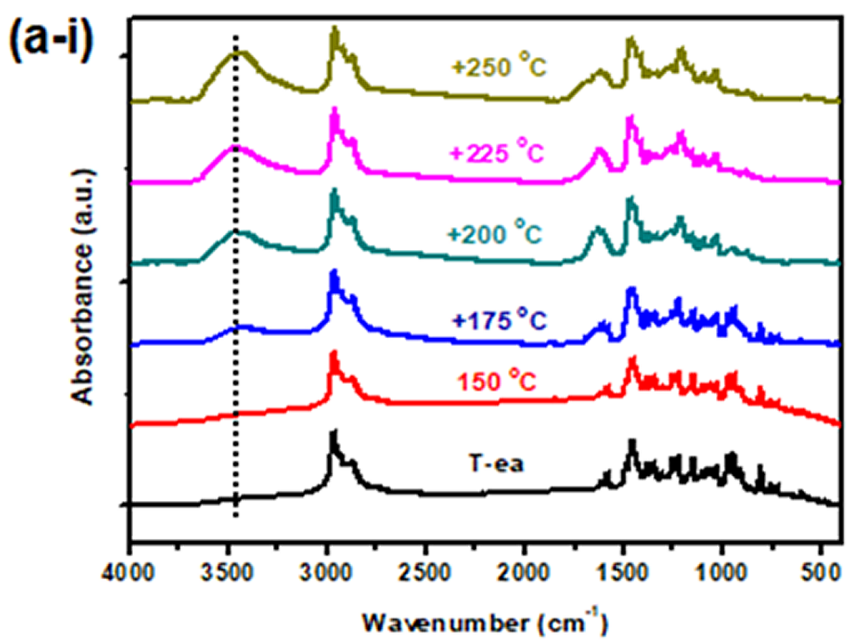

(b-i)

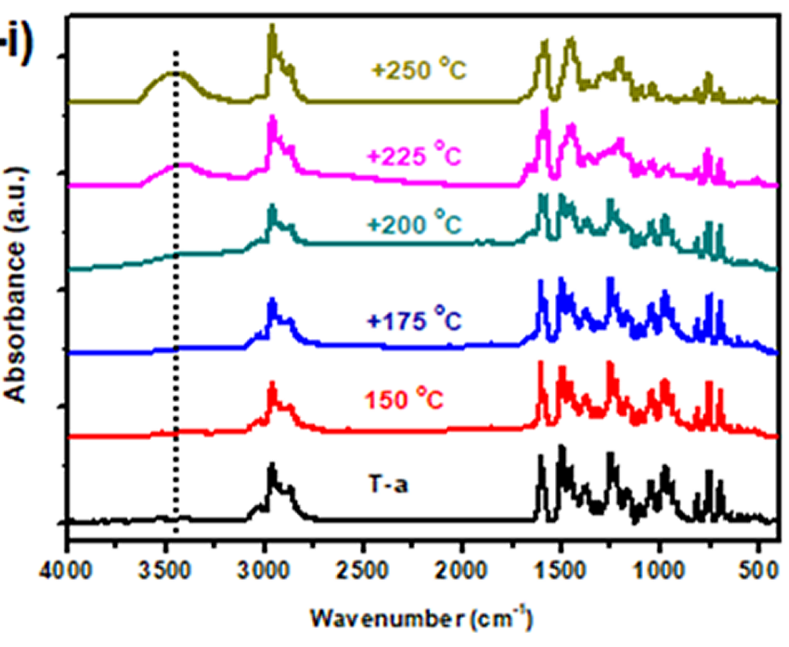

(c-i)

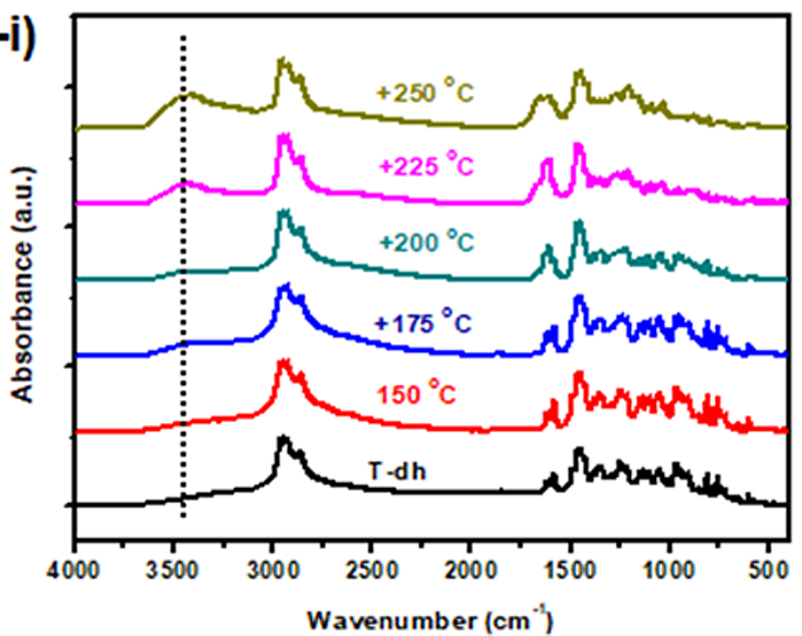

C-O-C

C-H

(a-ii)

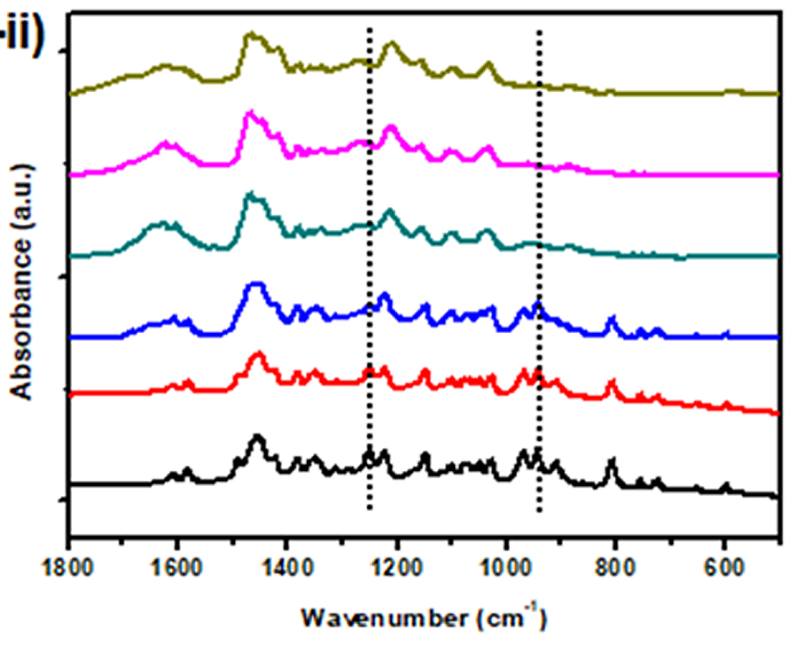

(b-ii)

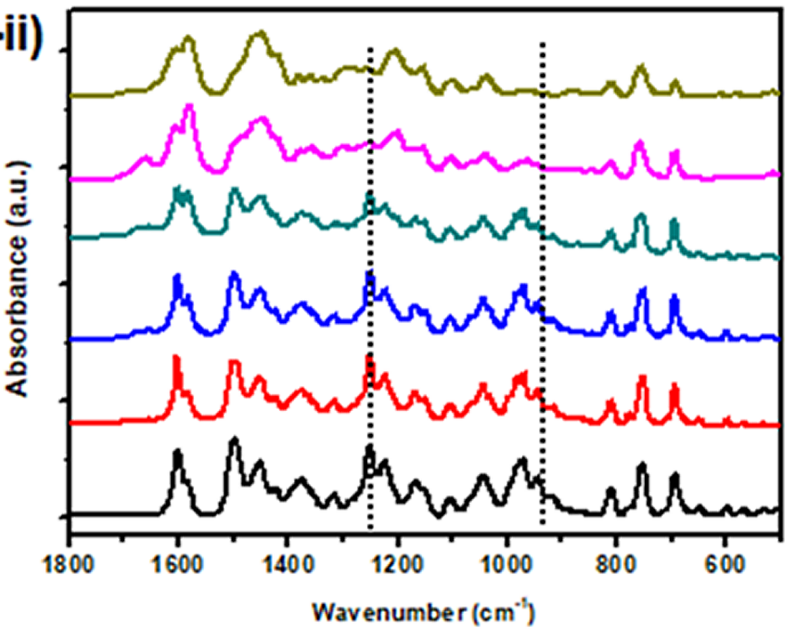

(c-ii)

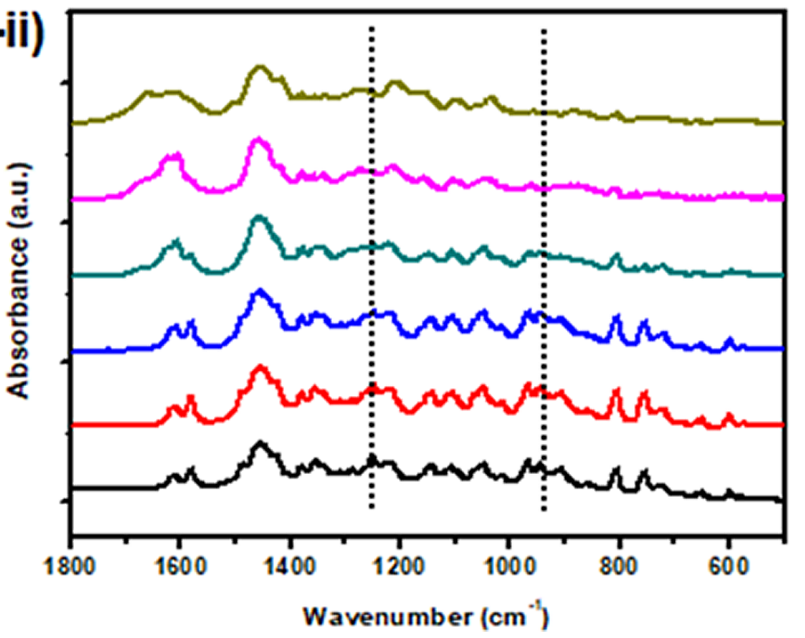

Figure 6. FTIR spectra of (a) PT-ea, (b) PT-a, and (c) PT-dh after each thermal curing step (i) in the range of $4000-400 \mathrm{~cm}^{-1}$ and (ii) in the range of $2000-400 \mathrm{~cm}^{-1}$. [Color figure can be viewed at wileyonlinelibrary.com]

Polymerization of the Thymol-Based Bio-Benzoxazine Resins by Thermal Curing

The typical polymerization reaction to obtain polybenzoxazines is based on the opening of oxazine ring and crosslinking of the molecules by thermal curing. ${ }^{1}$ Here, $\mathrm{T}-\mathrm{ea}, \mathrm{T}-\mathrm{a}$, and $\mathrm{T}-\mathrm{dh}$ were polymerized by thermally initiated ring-opening reaction performed stepwise at $150,175,200,225$, and $250{ }^{\circ} \mathrm{C}$, as a result, polybenzoxazines PT-ea, PT-a, and PT-dh were obtained, respectively. After thermal curing, polybenzoxazine crosslinked networks (PT-ea, PT-a, and PT-dh) were obtained as dark brown 

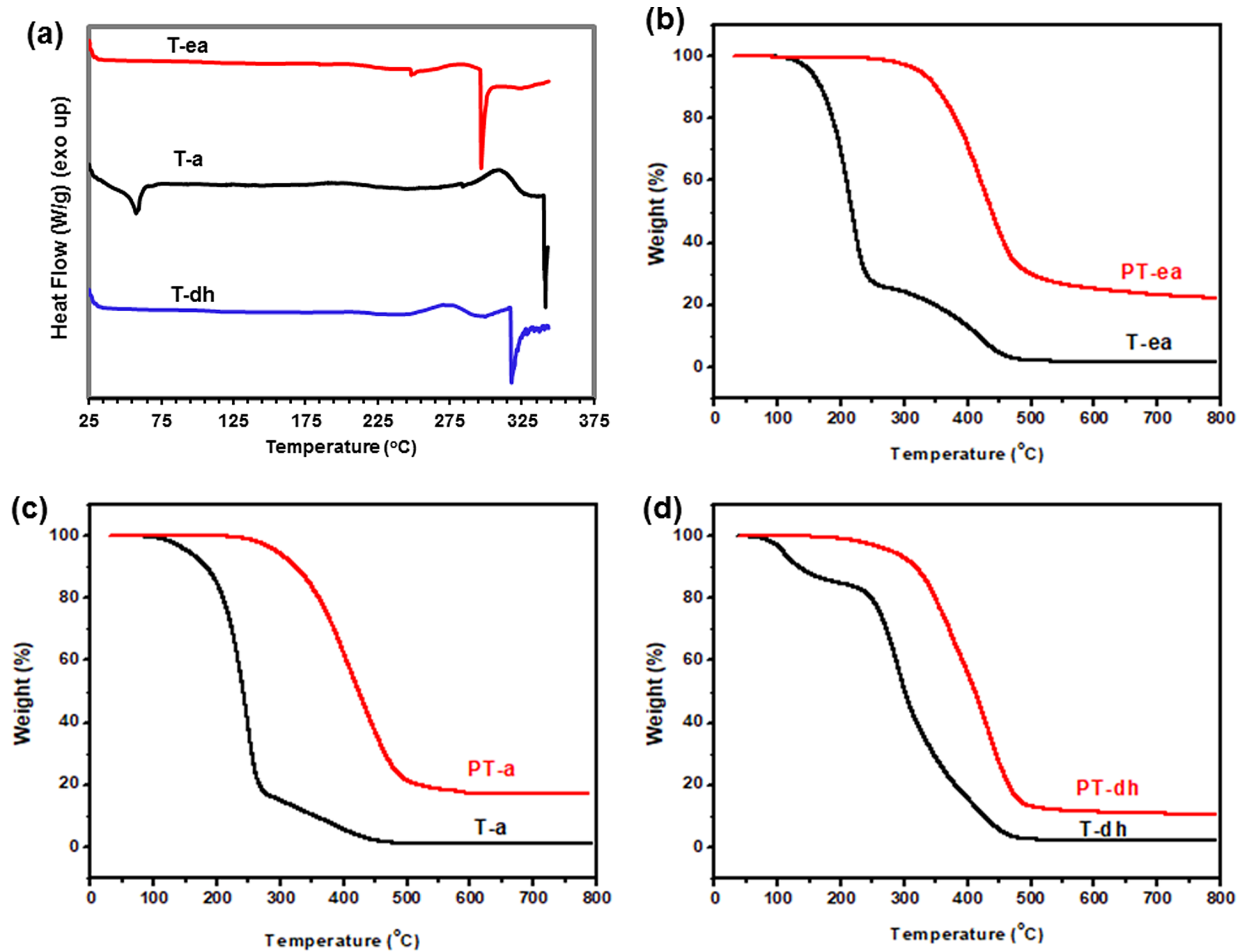

Figure 7. (a) DSC curves of T-ea, T-a, and T-dh and TGA thermograms of (b) T-ea and PT-ea; (c) T-a and PT-a; and (d) T-dh and PT-dh. [Color figure can be viewed at wileyonlinelibrary.com]

color which is a typical color of polybenzoxazines when they are thermally cured. The molecular structures of T-ea, T-a, and T-dh and their predicted crosslinked polymers PT-ea, PT-a, and PT-dh are represented in Figure 5. The polymerization reaction (ring opening and crosslinking) by stepwise curing was monitored by FTIR spectroscopy and FTIR spectrum of each sample was recorded after each step of thermal curing. The ring-opening and crosslinking reactions were investigated by considering the characteristic absorbance peaks of the oxazine ring which are asymmetric stretching vibration of $\mathrm{C}-\mathrm{O}-\mathrm{C}$ and $\mathrm{C}-\mathrm{H}$ out-of-plane deformation mode of the benzene ring attached to the oxazine ring. Because oxazine ring opens by heating at temperatures in the range between 160 and $220{ }^{\circ} \mathrm{C}^{52}$ and intensity of the peaks decreases with the increasing temperature. FTIR spectra of stepwised cured $\left(150,175,200,225\right.$, and $250{ }^{\circ} \mathrm{C}, 1 \mathrm{~h}$ for each temperature) PT-ea, PT-a, and PT-dh are given in Figure 6. As displayed on the spectra, intensity of the characteristic oxazine ring absorbance peaks decreased with increasing temperature and almost disappeared when heated at $250{ }^{\circ} \mathrm{C}$. In addition, very broad absorbance peak at around $3400 \mathrm{~cm}^{-1}$ was observed especially after heating $200{ }^{\circ} \mathrm{C}$ and the intensity/broadness of this peak increased with increasing temperature. For PT-ea, PT-a, and PT-dh, this broadband mainly may be attributed the combination of interactions; $\mathrm{O}^{-} \ldots \mathrm{H}^{+} \mathrm{N}$ intermolecular hydrogen bonding, $\mathrm{OH} . . \mathrm{N}$ intermolecular hydrogen bonding, $\mathrm{OH}$...O intramolecular hydrogen bonding and $\mathrm{OH} . . . \pi$ intermolecular hydrogen bonding. ${ }^{53,54}$ The increase intensity of this peak with high temperature heating suggested the opening of the oxazine rings as a result polymerization for each bio-benzoxazine resins.

Furthermore, cure analysis of the bio-based benzoxazines were studied using DSC technique to confirm the feasibility of curing method. Figure 7(a) displays the DSC curves of T-ea, T-a, and T$\mathrm{dh}$. The exothermic peaks associated with benzoxazine ringopening and crosslinking temperature are observed beyond $275{ }^{\circ} \mathrm{C}$ for all samples. The highest exothermic peak was observed in $\mathrm{T}$-a with $310^{\circ} \mathrm{C}$, while $\mathrm{T}$-ea and $\mathrm{T}$-dh resins show this peak at 286 and $275{ }^{\circ} \mathrm{C}$, respectively. Following that, the thermal properties of the thymol-based bio-benzoxazine resins (T-ea, T-a, and T-dh) and their corresponding polybenzoxazines (PT-ea, PT-a, and PT-dh) were investigated by TGA [Figure 7(ac)]. The thymol-based benzoxazine resins have shown two-step 
Table II. Thermal Properties of the Thymol-Based Bio-Benzoxazines Before and After Thermal Curing

\begin{tabular}{lllll}
\hline Benzoxazine & $\mathrm{T}_{5}\left({ }^{\circ} \mathrm{C}\right)$ & $\mathrm{T}_{15}\left({ }^{\circ} \mathrm{C}\right)$ & $\mathrm{T}_{\mathrm{d}}\left({ }^{\circ} \mathrm{C}\right)$ & $\mathrm{CY}(\%)$ \\
\hline T-ea & 151 & 178 & 317 & 1.5 \\
PT-ea & 324 & 366 & 431 & 22.2 \\
T-a & 154 & 199 & 319 & 0.9 \\
PT-a & 298 & 344 & 436 & 17.6 \\
T-dh & 126 & 198 & 336 & 0.6 \\
PT-dh & 281 & 336 & 432 & 12.0 \\
\hline
\end{tabular}

thermal decomposition profile while their polybenzoxazines have only one-step thermal decomposition indicating the successful polymerization under applied curing temperatures. Table II summarizes the thermal properties of the thymol-based biobenzoxazines and their corresponding polybenzoxazines obtained from TGA profiles. The main decomposition temperatures of these three polybenzoxazines were quite similar to each other. The CYs were also calculated from the TGA profiles in Figure 7. Compared to pristine thymol-based bio-benzoxazines, a notable $\mathrm{CY}$ increase was observed for the corresponding polybenzoxazines indicated that the crosslinking of benzoxazine resins by applied stepwised thermal curing process was successful. The CY of PT-ea (22.2\%) was highest compared to PT-a (17.6\%) and PT$\mathrm{dh}(12.0 \%)$, most probably because of the high density of crosslinking due to the short chain of ethyl amine. On the other hand, PT-dh (12.0\%) has shown the lowest CY since the precursor amine (1,6-diaminohexane) used for this sample has longer aliphatic unit than the ethylamine-based polybenzoxazines.

Consequently, the main focus of this study was to introduce thymol-based bio-benzoxazines that are produced by different amine compounds and the preparation of their corresponding polybenzoxazine structures. The mechanical properties of these crosslinked polybenzoxazines networks were also attempted to investigate but preliminary studies have shown that thymol-based polybenzoxazines have quite brittle nature that limits the study since it is extremely challenging to obtain a uniform structure for measurements. This drawback also limits the estimation of crosslinking density of polybenzoxazines. However, we have successfully demonstrated that thymol-based bio-benzoxazines could be easily synthesized using solvent-free technique from different amine compounds and their polymerized structures can be obtained by traditional curing method. The resulting thymolbased polybenzoxazine networks showed enhanced thermal stability compared to their corresponding uncured resins.

\section{CONCLUSIONS}

Here, novel bio-benzoxazine resins were synthesized from naturally existing phenolic compound thymol, paraformaldehyde and three different amines with different functionalities: ethyl amine (aliphatic), aniline (aromatic), and 1,6-diaminohexane (difunctional aliphatic). Molecular structural characterizations of the novel thymol-based bio-benzoxazine resins were performed by ${ }^{1} \mathrm{H}-\mathrm{NMR}$ and FTIR spectroscopy confirming the successful synthesis of these thymol-based benzoxazine resins. In addition, the chemical composition and molecular weight of the thymol-based benzoxazine resins are confirmed by elemental analysis and mass spectroscopy. Curing studies of all thymol-based bio-benzoxazines were carried out stepwise in the range of $150-250{ }^{\circ} \mathrm{C}(150,175$, 200,225 , and $250^{\circ} \mathrm{C}, 1 \mathrm{~h}$ for each temperature). According to the FTIR spectra recorded at each curing step of thymol bio-benzoxazines, ring opening and crosslinking of the oxazine ring were achieved by heating up to $250{ }^{\circ} \mathrm{C}$. Although no significant difference was observed on thermal stability $\left(\mathrm{T}_{5}, \mathrm{~T}_{15}\right.$, and $\mathrm{T}_{\mathrm{d}}$ values) of thymol-based polybenzoxazines having different amine precursors, PT-ea has the highest CY when compared to PT-a and PT-dh. In this study, we aimed to use plant-derived phenolic compound (i.e., thymol) as a phenolic derivative and we successfully achieved synthesis of bio-based benzoxazine resins from thymol.

\section{CONFLICT OF INTERESTS}

The authors declare that they have no conflicts of interest.

\section{REFERENCES}

1. Sun, L.; Zhang, K.; Min, C.; Liu, Y.; Wang, Y.; Zhang, J.; Li, S. Thermochim. Acta. 2018, 668, 1.

2. Ghosh, N. N.; Kiskan, B.; Yagci, Y. Prog. Polym. Sci. 2007, 32, 1344.

3. Yagci, Y.; Kiskan, B.; Ghosh, N. N. J. Polym. Sci. Part A: Polym. Chem. 2009, 47, 5565.

4. Ishida, H.; Rodriguez, Y. Polymer. 1995, 36, 3151.

5. Takeichi, T.; Kano, T.; Agag, T. Polymer. 2005, 46, 12172.

6. Wang, Y. X.; Ishida, H. Polymer. 1999, 40, 4563.

7. Ishida, H. Handbook of Benzoxazine Resins; Elsevier, Amsterdam, 2011.

8. Lligadas, G.; Tuzun, A.; Ronda, J. C.; Galia, M.; Cadiz, V. Polym. Chem. 2014, 5, 6636.

9. Sharma, P.; Kumar, D.; Roy, P. K. Polymer. 2018, 138, 343.

10. Ribeiro, F. W. M.; Kotzebue, L. R. V.; Oliveira, J. R.; Maia, F. J. N.; Mazzetto, S. E.; Lomonaco, D. J. Therm. Anal. Calorim. 2017, 129, 281.

11. Patil, D. M.; Phalak, G. A.; Mhaske, S. J. Coat. Technol. Res. 2017, 14, 517.

12. Patil, D. M.; Phalak, G. A.; Mhaske, S. Prog. Org. Coat. 2017, 105, 18.

13. Šebenik, U.; Krajnc, M. Eur. Polym. J. 2016, 81, 138.

14. Thirukumaran, P.; Sathiyamoorthi, R.; Shakila Parveen, A.; Sarojadevi, M. Polym. Compos. 2016, 37, 573.

15. Šebenik, U.; Krajnc, M. Polymer. 2015, 76, 203.

16. Rao, B.; Palanisamy, A. Eur. Polym. J. 2013, 49, 2365.

17. Lochab, B.; Varma, I. K.; Bijwe, J. J. Therm. Anal. Calorim. 2012, 107, 661.

18. Rao, B.; Palanisamy, A. React. Funct. Polym. 2011, 71, 148.

19. Lochab, B.; Varma, I. K.; Bijwe, J. J. Therm. Anal. Calorim. 2010, 102, 769.

20. Minigher, A.; Benedetti, E.; De, O. G.; Campaner, P.; Aroulmoji, V. Nat. Prod. Commun. 2009, 4, 521. 
21. Calò, E.; Maffezzoli, A.; Mele, G.; Martina, F.; Mazzetto, S. E.; Tarzia, A.; Stifani, C. Green Chem. 2007, 9, 754.

22. Phalak, G. A.; Patil, D. M.; Mhaske, S. Eur. Polym. J. 2017, $88,93$.

23. Ručigaj, A.; Gradišar, Š.; Krajnc, M. e-Polymers. 2016, 16, 199.

24. Periyasamy, T.; Asrafali, S. P.; Muthusamy, S. New J. Chem. 2015, 39, 1691.

25. Wang, C.; Sun, J.; Liu, X.; Sudo, A.; Endo, T. Green Chem. 2012, 14, 2799.

26. Xu, H.; Zhang, W.; Lu, Z.; Zhang, G. RSC Adv. 2013, 3, 3677.

27. Xu, H.; Lu, Z.; Zhang, G. RSC Adv. 2012, 2, 2768.

28. Thirukumaran, P.; Shakila, A.; Muthusamy, S. RSC Adv. 2014, 4, 7959.

29. Dumas, L.; Bonnaud, L.; Olivier, M.; Poorteman, M.; Dubois, P. J. Mater. Chem. A. 2015, 3, 6012.

30. Thirukumaran, P.; Shakila Parveen, A.; Sarojadevi, M. ACS Sustain. Chem. Eng. 2014, 2, 2790.

31. Fache, M.; Boutevin, B.; Caillol, S. Eur. Polym. J. 2015, $68,488$.

32. Li, S.; Yan, S. RSC Adv. 2015, 5, 61808.

33. Dumas, L.; Bonnaud, L.; Olivier, M.; Poorteman, M.; Dubois, P. Eur. Polym. J. 2016, 75, 486.

34. Dumas, L.; Bonnaud, L.; Olivier, M.; Poorteman, M.; Dubois, P. Green Chem. 2016, 18, 4954.

35. Llevot, A.; Grau, E.; Carlotti, S.; Grelier, S.; Cramail, H. Macromol. Rapid Commun. 2016, 37, 9.

36. Dumas, L.; Bonnaud, L.; Olivier, M.; Poorteman, M.; Dubois, P. Eur. Polym. J. 2016, 81, 337.

37. Froimowicz, P.; Arza, C. R.; Han, L.; Ishida, H. ChemSusChem. 2016, 9, 1921.

38. Liu, X.; Zhang, R.; Li, T.; Zhu, P.; Zhuang, Q. ACS Sustain. Chem. Eng. 2017, 5, 10682.
39. Muthukaruppan, A.; Arumugam, H.; Krishnan, S.; Kannan, K.; Chavali, M. J. Polym. Res. 2018, 25, 163.

40. Dai, J.; Teng, N.; Peng, Y.; Liu, Y.; Cao, L.; Zhu, J.; Liu, X. ChemSusChem. 2018, 11, 3175.

41. Shen, X.; Dai, J.; Liu, Y.; Liu, X.; Zhu, J. Polymer. 2017, 122,258

42. Dai, J.; Teng, N.; Shen, X.; Liu, Y.; Cao, L.; Zhu, J.; Liu, X. Ind. Eng. Chem. Res. 2018, 57, 3091.

43. Wilbon, P. A.; Chu, F.; Tang, C. Macromol. Rapid Commun. 2013, 34, 8.

44. Wang, M.; Leitch, M.; Xu, C. Eur. Polym. J. 2009, 45, 3380.

45. Stemmelen, M.; Pessel, F.; Lapinte, V.; Caillol, S.; Habas, J. P.; Robin, J. J. J. Polym. Sci. Part A: Polym. Chem. 2011, 49, 2434.

46. Yanishlieva, N. V.; Marinova, E. M.; Gordon, M. H.; Raneva, V. G. Food Chem. 1999, 64, 59.

47. Celebioglu, A.; Yildiz, Z. I.; Uyar, T. Food Res. Int. 2018, 106, 280.

48. Botelho, M. A.; Nogueira, N. A. P.; Bastos, G. M.; Fonseca, S. G. C.; Lemos, T. L. G.; Matos, F. J. A.; Montenegro, D.; Heukelbach, J.; Rao, V. S.; Brito, G. A. C. Braz. J. Med. Biol. Res. 2007, 40, 349.

49. Kfoury, M.; Landy, D.; Ruellan, S.; Auezova, L.; GreigeGerges, H.; Fourmentin, S. Beilstein J. Org. Chem. 2016, 12, 29.

50. Ning, X.; Ishida, H. J. Polym. Sci. Part A: Polym. Chem. 1994, 32, 1121.

51. Dunkers, J.; Ishida, H. Spectrochim. Acta Part A: Mol. Biomol. Spectrosc. 1995, 51, 1061.

52. Ning, X.; Ishida, H. J. Polym. Sci. Part B: Polym. Phys. 1994, 32, 921.

53. Ishida, H.; Allen, D. J. J. Polym. Sci. Part B: Polym. Phys. 1996, 34, 1019.

54. Kim, H.-D.; Ishida, H. J. Phys. Chem. A. 2002, 106, 3271. 